\title{
Measurement of spinal curvatures during sitting on a rehabilitation ball versus stool
}

\author{
Sandalyeye kiyasla rehabilitasyon topuna oturma sırasında omurga eğiminin ölçümü \\ Aleksandra Truszczyńska, Justyna Drzał-Grabiec, Paulina Cichosz, Zbigniew Trzaskoma \\ Józef Piłsudski University of Physical Education in Warsaw, Faculty of Rehabilitation, Marymoncka St. Warsaw, Poland \\ Received / Geliş tarihi: May 2015 Accepted / Kabul tarihi: July 2015
}

\begin{abstract}
Objectives: This study aims to compare the extent of the spine curvatures in the sagittal plane during corrected sitting on a rehabilitation ball and during sitting on a chair without a backrest.

Patients and methods: The study group consisted of 57 subjects ( 23 males, 34 females; mean age $24.7 \pm 2.3$ years; range 20 to 32 years). The Moiré method was used to assess the body posture. The tests were conducted using the apparatus for computer assessment of the body posture MORA 4 Generation. The spine curvature was assessed in two positions: on a chair without a backrest and on a rehabilitation ball.

Results: There was a statistically significant difference between the depth of thoracic kyphosis in both positions $(\mathrm{p}=0.003)$. A greater depth of thoracic kyphosis was recorded in the sitting position on a chair $\left(4.3 \pm 5.3^{\circ}\right)$ than in the sitting position on a rehabilitation ball $\left(0.3 \pm 7.0^{\circ}\right)$. A statistically significant difference was observed between the values of GAMMA in two consecutive measurements $(\mathrm{p}=0.049)$. Higher values of this parameter were noted in the sitting position on a rehabilitation ball $\left(33.8 \pm 22.6^{\circ}\right)$ versus on a chair $\left(26.5 \pm 22.8^{\circ}\right)$.

Conclusion: Sitting on a rehabilitation ball as a corrective and therapeutic exercise should be preceded by teaching the patient how to adopt the correct position. Then, rehabilitation balls can become an alternative to chairs.
\end{abstract}

Keywords: Back pain; Moiré topography; posture; spine.

\section{$\ddot{O Z Z}$}

Amaç: Bu çalışmada rehabilitasyon topu üzerinde düzeltilmiş oturma ve desteksiz bir sandalyeye oturma sırasında sagital düzlemde omurga eğiminin derecesi karşılaştırıldı.


değerlendirmek için Moiré yöntemi kullanıldı. Testler, vücut postürünün bilgisayarlı değerlendirmesi MORA 4 Jenerasyon aparatı ile gerçekleştirildi. Omurga eğimi iki pozisyonda değerlendirildi: desteksiz sandalyede ve rehabilitasyon topunda.

Bulgular: Her iki pozisyonda da torakstaki kifoz derinliği arasında istatistiksel olarak anlamlı bir fark vardı ( $\mathrm{p}=0.003)$. Rehabilitasyon topunda oturma pozisyonuna $\left(0.3 \pm 7.0^{\circ}\right)$ kıyasla, sandalyede oturma pozisyonunda $\left(4.3 \pm 5.3^{\circ}\right)$ daha yüksek toraks kifoz derinliği kaydedildi. İki ardışık ölçümde GAMMA değerleri arasında istatistiksel açıdan anlamlı bir fark gözlendi $(\mathrm{p}=0.049)$. Bu parametrede sandalyeye kıyasla $\left(26.5 \pm 22.8^{\circ}\right)$, rehabilitasyon topunda oturma pozisyonunda $\left(33.8 \pm 22.6^{\circ}\right)$ daha yüksek değerler kaydedildi.

Sonuç: Düzeltici ve terapötik egzersiz olarak rehabilitasyon topuna oturma, hastanın doğru pozisyonu alacak şekilde öğretilmesi ile gerçekleştirilmelidir. Ardından, rehabilitasyon topları sandalyelere bir alternatif olabilir.

Anabtar sözcükler: Bel ağrısı; Moiré topografisi; postür; omurga.

Corresponding author / İletişim adresi: Aleksandra Truszczyńska, PhD. Józef Piłsudski University of Physical Education in Warsaw, Faculty of Rehabilitation, Marymoncka St. 34, 00-968 Warsaw, Poland. e-mail / e-posta: aleksandra.rapala@wp.pl 
Curvatures of the spine perform amortization functions and increase its strength. ${ }^{[1]}$ The position most commonly adopted by man is the sitting position, which is characterized by reduced or completely abolished angle of pelvis anteversion and also kyphotization of the whole spine. This is conducive to an overload of the supporting segments, stretching muscles and ligaments, especially in the lumbar spine. ${ }^{[2,3]}$ The frequency with which a contemporary man tends to adopt the sitting position makes specialists look for such conditions that will allow for the preservation of the physiological shape of the spine and diminishing of overload. ${ }^{[4]}$ The use of suitable equipment, such as an ergonomic stool, a rehabilitation ball, or a saddle chair, facilitates correcting the abnormal position of the spine. Due to its flexibility, lability, and stability, a rehabilitation ball is used in various vital human activities, including sitting and exercising. The use of a rehabilitation ball forces spine stabilization and subconscious activation of postural muscles. It also provides amortization during rapid movements, improves balance, integrates the functions of both hemispheres of the brain, increases concentration and coordination, reduces the mechanical load of the musculoskeletal system and the muscular system, and improves motor skills and mobility. Sitting and exercising on a rehabilitation ball are conducted in two systems: the body of the exercising person-the ball and the body of the exercising person a stable surface, which causes the ball to become the moving basis of the body. ${ }^{[3]}$

The changes in the sizes of spine curvatures occurring under the influence of external forces were the subject of research conducted by, among others, Li et al. ${ }^{[5]}$ who in a study of 13 -year-old girls with idiopathic scoliosis used an ultrasound scan and measured the time and appearance of the changes in the Cobb angle both after putting on a spinal orthosis and after taking it off. The authors believed that viscoelastic properties and high susceptibility of the spine to mechanical deformations were probably the main cause of the delay which occurs between the beginning of the influence of external forces and the appearance of critical variations in the sizes of spine curvatures.

The use of a rehabilitation ball in correcting human body posture has been investigated by many authors in various aspects, for instance as a new form of exercising, ${ }^{[3]}$ a therapeutic instrument in patients with chronic pain in the lumbar spine, ${ }^{[6,7]}$ or an assessment of trunk muscle activity. ${ }^{[8,9]}$ Gregory et al., ${ }^{[10]}$ Kingma and Van Dieen, ${ }^{[11]}$ Escamilla et al. ${ }^{[12]}$ as well as McGill et al. $^{[13]}$ studied the differences in muscle activity between sitting on a rehabilitation ball and sitting on a chair, and Carter et al. ${ }^{[14]}$ determined the impact of exercising on a rehabilitation ball on balance control. Biomechanical evaluation of the sitting position on the ball was conducted by Schult et al. ${ }^{[15]}$ Al-Eisa et al..$^{[16]}$ and Jackson et al. ${ }^{[6]}$ investigated the feeling of discomfort experienced while exercising on a rehabilitation ball.

In the available literature, no data was found on the effect of the sitting position and exercising on a rehabilitation ball on the shape of the spine, therefore in this study we aims to compare the sizes of spine curvatures in the sagittal plane during corrected sitting on a rehabilitation ball and sitting on a chair without a backrest.

\section{PATIENTS AND METHODS}

The consent for performing the study was granted by the Senate Ethics Committee for Scientific Research at Jozef Pilsudski University of Physical Education in Warsaw, Poland. A written informed consent was obtained from each patient. The study was conducted in accordance with the principles of the Declaration of Helsinki. The study group included 57 people (23 males, 34 females; mean age $24.7 \pm 2.3$ years; range 20 to 32 years) who responded to the invitation to participate and agreed to be involved in the proposed research study. Examinations were performed in parallel in two positions: on a chair without a backrest and on a rehabilitation ball. The height of the seat of the chair and of the ball was adjusted to the body height of the examined persons, which was determined on the basis of anthropometric parameters of each of the subjects assessed immediately before testing. A rule was adopted that the angle of the flexion in the hips and knees should be 90 degrees.

The anthropometric points: spinous processes, lower corners of the scapulae, peak of kyphosis, the deepest point of lordosis, transition of kyphosis into lordosis, and posterior iliac spines were determined by palpation and marked with a dermatograph by a physiotherapist. The study was carried out using MORA 4 Generation, CQ Electronik System (Swierc, Poland). The measuring device uses photogrammetry, that is, performs anthropometric calculations based on the photograph of the studied surface. The photogrammetric method was used to evaluate body posture using the phenomenon of the projection chamber. The image in position without twisting of the trunk or pelvis was taken, and the anthropometric 
points were transferred on to a photogram on the computer screen. Based on the marked points, the computer defined the parameters describing the body posture by assessing the distance of the selected points from the camera. The patient was positioned at a distance of $2.6 \mathrm{~m}$ from the camera while the device projects lines of strictly defined parameters onto the patient's back, allowing a spatial image to be obtained. These lines reach the patient's back at a specific angle and are distorted depending on the distance of a given point from the device. The computer records line image distortions and numerical algorithms are used to convert them into a contour map of the surface. In optics, the physical basis of this method is called the Moire phenomenon. ${ }^{[17]}$

Scientific studies have confirmed that the results obtained by the photogrammetric method are very close to X-ray outcomes. ${ }^{[18,19]}$

Photogrammetry has been demonstrated to be a reliable method for the measurement of postural deviations from the posterior and lateral views. Reliability of photogrammetry was also confirmed in the evaluation of the postural aspects of individuals with structural scoliosis. ${ }^{[20]}$

According to the authors, the intrarater and interrater evaluations of standing sagittal posture of the cervical spine and shoulders by photogrammetry was reliable. ${ }^{[21,22]}$ Schroeder et al. ${ }^{[23]}$ found a lower reproducibility for the frontal plane, raster stereography is considered to be a reliable method for the noninvasive, three-dimensional assessment of spinal alignment in normal non-scoliotic individuals in the sagittal plane and partly for scoliosis parameters, which fulfills scientific as well as practical recommendations for spine shape screening and monitoring, but crosssectional or follow-up effect analyses should take into account the degree of reliability differing in various spine shape parameters.

It is a non-invasive examination, and therefore it can be repeated without limitations and applied in cases where there is no indication to perform radiological examination. ${ }^{[24]}$ The tests were conducted using the apparatus for computer assessment of the body posture MORA 4 Generation provided by CQ Elektronik System (Swierc, Poland), which combines the advantages of spatial analysis systems MORA/ISIS. They were performed in parallel in two positions: on a chair without a backrest and on a rehabilitation ball. The height of the seat of the chair and of the ball was adjusted to the body height of the examined persons, which was determined on the basis of anthropometric parameters of each of the subjects assessed immediately before testing. A rule was adopted that the angle of the bend in the hips and knees should be 90 degrees.

The following variables were analyzed:

- ALFA-lumbosacral region inclination $\left(^{\circ}\right)$

- BETA-thoracolumbar region inclination ( $\left.{ }^{\circ}\right)$

- GAMMA-upper thoracic region inclination ( $\left.{ }^{\circ}\right)$

- KPT-sagittal inclination of the trunk $\left(^{\circ}\right)$

- KKP-thoracic kyphosis $\left(^{\circ}\right)$

- RKP-length of C7-PL. Height of kyphosis calculated between $\mathrm{C} 7$ and PL (\%)

- GKP-depth of KP-PL $\left(^{\circ}\right)$

- KLL-lumbar lordosis $\left(^{\circ}\right)$

- GLL-depth of LL-PL (mm)

- KNT-coronal inclination of the trunk $\left(^{\circ}\right)$

- KLB-angle of the shoulder line ( $\mathrm{mm}$ )

- UL-difference in the height of the lower corners of scapulae (inclination) ( $\mathrm{mm}$ )

- UB-difference in the depth of the lower corners of scapulae (torsion) (mm)

- OL-difference in the deflection of the lower corners of scapulae from the spine (\%)

- KNM-pelvic inclination angle $(\mathrm{mm})$

- KSM-pelvic rotation angle $(\mathrm{mm})$.

The method of determining the above-mentioned parameters is shown in Figure 1.

\section{Statistical analysis}

To compare the results obtained in the two positions paired samples Student's t-test was used for dependent variables. Statistica version 10.0 software (StatSoft, Inc., Paris, France) was used for the purpose of statistical analysis.

The following assumptions were made:

- $\mathrm{p}<0.05$, significant difference $\left(^{*}\right.$;

- $\mathrm{p}<0.01$, highly significant difference $\left.{ }^{* *}\right)$;

- $\mathrm{p}<0.001$, very highly significant difference $\left.{ }^{(* *}\right)$.

\section{RESULTS}

The biometric data of the examined persons are summarized in Table 1. The measurements results concerning the curvatures in two different positions are shown in Table 2.

The statistical analysis with the paired samples t-test detected a very highly statistically significant 


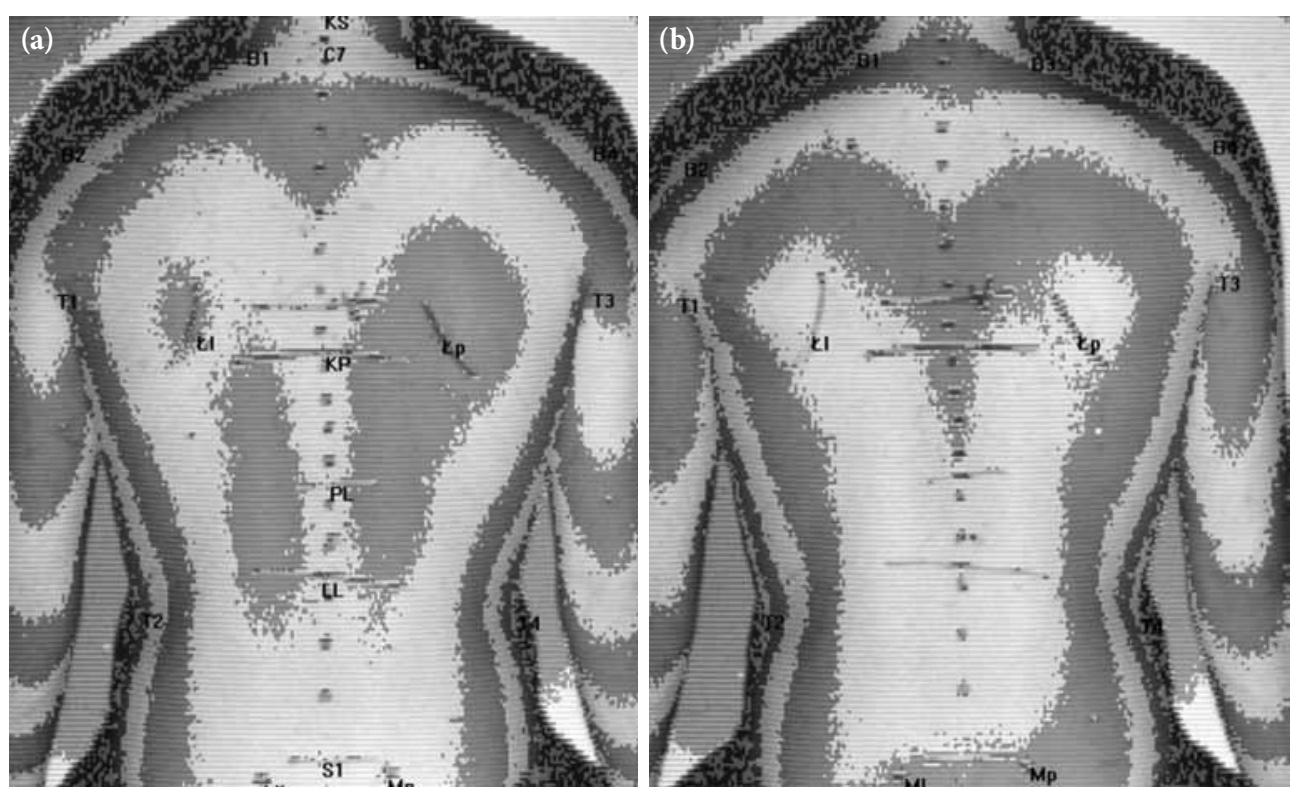

Figure 1. Sample image of the spine using the projection moiré method (a) posture on the stool, (b) posture on the ball.

difference $(\mathrm{p}=0.003)$ between the depth of thoracic kyphosis in both positions assumed by the subjects. A greater depth of thoracic kyphosis was recorded in the sitting position on a chair $\left(4.3 \pm 5.3^{\circ}\right)$ than in the sitting position on a rehabilitation ball $\left(0.3 \pm 7.0^{\circ}\right)$. A larger flattening of kyphosis occurred while the participants were sitting on the rehabilitation ball.

A statistically significant difference was proven $(p=0.049)$ between the values of GAMMA in two consecutive measurements. Higher values of this parameter were noted in the position involving a rehabilitation ball $\left(33.8 \pm 22.6^{\circ}\right)$ compared to the sitting position on a chair $\left(26.5 \pm 22.8^{\circ}\right)$. The inclination of the upper thoracic spine increased while sitting on a rehabilitation ball. A statistically significant difference was shown $(p=0.019)$ between the inclination of the trunk in the sitting position on a chair and sitting on a rehabilitation ball. Greater inclination was noted in the sitting position on a rehabilitation ball $\left(-3.6 \pm 17.9^{\circ}\right)$ compared to the sitting position on a chair $\left(-11.9 \pm 15.7^{\circ}\right)$.

Table 1. The biometric data of the examined persons

\begin{tabular}{lccc}
\hline Statistical value & Mean \pm SD & Median & Min.-Max. \\
\hline Age (years) & $24.7 \pm 2.3$ & 24.0 & $20.0-32.0$ \\
Body height $(\mathrm{cm})$ & $172.2 \pm 9.5$ & 170.0 & $152.0-195.0$ \\
Body weight $(\mathrm{kg})$ & $67.3 \pm 13.8$ & 64.0 & $47.0-115.0$ \\
BMI $\left(\mathrm{kg} / \mathrm{m}^{2}\right)$ & $22.5 \pm 3.0$ & 22.1 & $18.9-32.5$ \\
\hline
\end{tabular}

SD: Standard deviation; Min.: Minimum; Max.: Maximum; BMI: Body mass index.
A statistically significant difference was also observed between the depth values describing lumbar lordosis in the analyzed positions and higher values of this variable were recorded when the participants were sitting on the rehabilitation ball $(-0.4 \pm 2.7 \mathrm{~mm})$ $(\mathrm{p}=0.017)$.

\section{DISCUSSION}

Our results indicate flattening of thoracic kyphosis and lumbar lordosis and increased inclination of the trunk in a seated position on the rehabilitation ball. The flattening of the physiological curvatures of the spine is a result of changes in the position meant to help maintain balance on an unstable surface, as evidenced by the increased inclination of the trunk. Kyphosis and lordosis are responsible for the amortizationrelated functions of the spine and as a result of their flattening these functions are disturbed, which leads to an increased predisposition as regards to overloads and back pain. ${ }^{[25]}$

Flexible rehabilitation balls made of soft yet durable material force conscious concentration used to maintain the correct posture and perform smooth movements. It may be a tool for stretching or relaxing the body. It also constitutes an alternative or a complement to office chairs. ${ }^{[3]}$

O'Sullivan et al. ${ }^{\left[{ }^{[9]}\right.}$ showed that sitting on an unstable surface has no significant effect on trunk muscle 
Table 2. The values of the variables analyzed in two different positions (position 1 - corrected sitting on a chair, position 2 - sitting on a rehabilitation ball)

\begin{tabular}{|c|c|c|c|c|c|c|}
\hline \multirow[b]{2}{*}{ Variable } & \multicolumn{2}{|c|}{ Position 1} & \multicolumn{2}{|c|}{ Position 2} & \multirow[b]{2}{*}{$\mathrm{t}$} & \multirow[b]{2}{*}{$p$} \\
\hline & Mean \pm SD & Median & Mean \pm SD & Median & & \\
\hline $\operatorname{ALFA}\left({ }^{\circ}\right)$ & $26.6 \pm 30.2$ & 6.2 & $18.5 \pm 25.3$ & 7.6 & 0.28 & 0.209 \\
\hline $\operatorname{BETA}\left({ }^{\circ}\right)$ & $2.6 \pm 1.8$ & 1.8 & $2.0 \pm 1.7$ & 1.6 & 1.73 & 0.091 \\
\hline GAMMA $\left(^{\circ}\right)$ & $26.5 \pm 22.8$ & 12.0 & $33.8 \pm 22.6$ & 48.0 & -1.69 & $0.049^{*}$ \\
\hline $\mathrm{KPT}\left({ }^{\circ}\right)$ & $-3.6 \pm 17.9$ & -1.5 & $-11.9 \pm 15.7$ & -6.0 & 2.47 & $0.019^{*}$ \\
\hline $\mathrm{KKP}\left({ }^{\circ}\right)$ & $151.3 \pm 21.8$ & 165.9 & $146.0 \pm 22.5$ & 131.9 & 1.24 & 0.223 \\
\hline RKP (\%) & $286.8 \pm 24.1$ & 291.1 & $287.9 \pm 29.7$ & 291.1 & -0.24 & 0.815 \\
\hline GKP $\left(^{\circ}\right)$ & $4.3 \pm 5.3$ & 3.0 & $0.3 \pm 7.0$ & 0.8 & 3.17 & $0.003^{\star \star}$ \\
\hline $\operatorname{KLL}\left({ }^{\circ}\right)$ & $199.0 \pm 34.0$ & 179.5 & $190.0 \pm 29.8$ & 175.9 & 1.26 & 0.216 \\
\hline GLL (mm) & $-2.1 \pm 4.6$ & -1.5 & $-0.4 \pm 2.7$ & -0.8 & -2.49 & $0.017^{\star}$ \\
\hline $\mathrm{KNT}\left({ }^{\circ}\right)$ & $-0.5 \pm 0.9$ & -0.4 & $-0.5 \pm 1.2$ & -0.5 & -0.47 & 0.639 \\
\hline $\mathrm{KLB}(\mathrm{mm})$ & $1.7 \pm 5.6$ & 0.0 & $1.8 \pm 5.6$ & 0.0 & 0.04 & 0.972 \\
\hline UL (mm) & $0.4 \pm 4.1$ & 0.0 & $0.0 \pm 4.5$ & 0.0 & 0.74 & 0.462 \\
\hline $\mathrm{UB}(\mathrm{mm})$ & $4.7 \pm 5.7$ & 5.3 & $4.9 \pm 6.8$ & 6.0 & -0.35 & 0.727 \\
\hline OL (\%) & $0.4 \pm 8.6$ & 0.0 & $0.1 \pm 8.7$ & 1.9 & 0.26 & 0.797 \\
\hline KNM (mm) & $0.0 \pm 5.7$ & 0.9 & $0.4 \pm 6.0$ & 0.0 & -0.66 & 0.512 \\
\hline KSM (mm) & $5.3 \pm 3.4$ & 6.0 & $5.1 \pm 4.2$ & 5.3 & 0.26 & 0.796 \\
\hline
\end{tabular}

SD: Standard deviation; ALFA: Lumbosacral region inclination; BETA: Thoracolumbar region inclination; GAMMA: Upper thoracic region inclination; KPT: Sagittal inclination of the trunk; KKP: Thoracic kyphosis; RKP: Length of C7-PL, height of kyphosis calculated between C7 and PL; GKP: Depth of KP-PL; KLL: Lumbar lordosis; GLL: Depth of LL-PL; KNT: Coronal inclination of the trunk; KLB: Angle of the shoulder line; UL: Difference in the height of the lower corners of scapulae (inclination); UB: Difference in the depth of the lower corners of scapulae (torsion); OL: Difference in the deflection of the lower corners of scapulae from the spine; KNM: Pelvic inclination angle; KSM: Pelvic rotation angle.

activation. Similar conclusions were formulated by Weaver et al. ${ }^{[26]}$ Studies on muscle activity with the electromyography (EMG) method demonstrated that there are no additional benefits and there is no difference between the activation of muscles while sitting on a chair and on a ball. However, the reduced activity of the rectus abdominis muscle and the external oblique muscle while sitting on the ball can favorably affect the functional recovery, e.g. in patients after a stroke. Rehabilitation on balls also reduces muscle tension, which is especially important in patients with excessive rigidity or spasticity.

Scott et al. ${ }^{[27]}$ found that the multifidus muscle activation was more effective when the study subjects were sitting on the ball than on a stable surface, which was reflected for example by an increase in its crosssection.

The investigations of Jackson et al. ${ }^{[6]}$ into the level of discomfort related to sitting on a ball, stability of sitting, trunk muscle activity level and shape of the lumbar spine section showed that both women and men reported complaints connected with the area of the back extensor muscle and transverse abdominal muscles.

Prolonged sitting on a ball, according to Gregory et al., ${ }^{[10]}$ causes discomfort in comparison to a stable position on an office chair. The level of discomfort can be minimized by learning proper, ergonomic sitting position and then keeping in mind the need for constant corrections while sitting on the ball and maintaining proper body posture. According to the analyzes of Vergara and Page, ${ }^{[28]}$ one of the major factors causing short-term lumbar section pain is lordosis adjustment and anteversion of the pelvis occurring in the sitting position. Frequent changes of position while sitting and providing back support can reduce back pain. These facts highlight that static muscle activity is a major cause of short-term back pain. These findings were supported by Al-Eisa et al. ${ }^{[16]}$ who came to similar conclusions, noting a decrease in cervical spine disorders among female students while they were sitting on a ball.

The research of Kingma and Van Dieen ${ }^{[1]}$ was devoted to a comparison of sitting while working at a computer in two positions made them conclude that a chair without a backrest does not cause greater mobility of the trunk, head or spine. An alternative to the chair can be a rehabilitation ball. The results of using electromyography (EMG) monitoring included the following conclusions: sitting on the ball causes an increase in trunk movements by $33 \%$ and lumbar muscles strain higher by $66 \%$. In addition, they observed lesser elongation of the spine during sitting on the rehabilitation ball than during sitting on the office chair. The spine was shortened by $2.6 \mathrm{~mm}$ after an hour of sitting on the rehabilitation ball, and by 
$1.5 \mathrm{~mm}$ following sitting on a chair also for an hour. Unstable support can stimulate the activation of the spine and upper extremities. At the same time, the lack of support for the spine and upper extremities while sitting on the ball causes an increase in the static load of the spine and the muscles of the shoulder girdle. In contrast to the muscles of the lumbar spine section, the thoracic muscles showed no significant activation when the study participants were sitting in any of the situations examined. Apart from that, the trapezius showed no significant tension in either case. During the test, there was much greater discomfort observed in both the cervical and lumbar spine section when the study subjects were sitting on the ball. ${ }^{[1]}$

Ainscough-Potts et al. ${ }^{[29]}$ used the EMG method for measuring deep muscles activity: the transversus abdominis and the internal oblique muscle in different positions (lying on the back, sitting passively on a chair, sitting on a ball and sitting on a ball with a lower limb raised). The results showed that there were no significant differences in the activation of both muscles while sitting on the ball and on the chair in a passive position. Elevation of one lower limb increased the tension of the transversus abdominis in comparison to the internal oblique muscle. On the basis of these measurements, it was demonstrated that both deep abdominal muscles react similarly to postural body changes. Jackson et al. ${ }^{[6]}$ found no influence of sitting on a "stability ball" on the improvement of body posture.

Despite the widespread use of rehabilitation balls instead of office chairs, there is no convincing evidence proving the effectiveness of this practice. People sitting on various kinds of equipment feel comfortable sitting in different positions, which may have an impact on pressure distribution between the intervertebral discs of the spine. Research results from McGill et al. ${ }^{[13]}$ indicated that prolonged sitting, both in static and dynamic conditions, does not have any considerable effect on the activation of muscles, spinal curvatures and broadly understood stability. They also found that sitting on the ball increases the contact of soft tissues of the human body with a ball in comparison with sitting on a chair. No significant differences were revealed in compression and stability between sitting on a rehabilitation ball and on a chair. In both conditions, during the long-term use of both kinds of equipment, no significant impact on paraspinal muscle activity was recorded. Both sitting on a rehabilitation ball and on a chair stimulate the deeper muscles more than the superficial ones.
According to Carter et al. ${ }^{[14]}$ balance training when used systematically improves the stability of the spine. Maintaining segmental control of the trunk ensures stability of the entire spine and reduction of adverse intersegmental movements. This serves to decrease the risk of back pain caused by soft tissue tension, as well as their deformation and compression.

Tudor-Locke et al. ${ }^{[30]}$ while looking for evidence of whether traditional office chairs should be replaced by equipment providing unstable sitting conditions, e.g. a rehabilitation ball, came to the conclusion that it can bring a lot of benefits. However, the potential users should learn the proper, corrected sitting position in this type of conditions. Other studies on the same aspect proved that people sitting on a ball, in comparison to people sitting on an office chair, perceived and corrected their posture better and experienced an increase in the level of their professional energy. ${ }^{[15]}$

In the current scientific literature there is a lack of studies regarding the influence of the sitting position on the rehabilitation ball on the shape of curvature of the spine. Our findings are the first evaluating the curvature of the spine in this position.

The results presented in this study report confirmed that assuming proper posture affects the parameters of the setting of the spine in the sagittal plane. It should be remembered that improper sitting position on a ball has a negative effect on the setting of individual segments of the spine.

The limitations of this study undoubtedly include the small size of the group, its nonuniformity in relation to sex and the small variation in the age of the participants. The measurements were performed only in the sagittal plane and in the case of evaluation of positional changes of the curvatures of the spine, which are multifaceted, it is quite insufficient. To examine in greater detail the changes in spinal curvatures that accompany the maintenance of the sitting position in different biomechanical conditions, further research should be carried out taking into account the measurements in all planes, performed in more numerous groups embracing participants of different ages and ensuring the possibility of analyzing the inter-sex differences.

\section{Key messages}

1. An important aspect of back pain prevention is ergonomic sitting posture. 
2. A rehabilitation ball enables better position of lumbar lordosis, but also leads to negative flattening of thoracic kyphosis.

3. For these reasons the use of a rehabilitation ball as a corrective and therapeutic exercise should be preceded by teaching the patient how to adopt the correct position.

4. Rehabilitation balls can become an alternative to office chairs.

\section{Conclusions}

1. Active correction of posture on a rehabilitation ball leads to the flattening of the physiological curvatures of the spine.

2. Static sitting on a ball requires constant monitoring of the body position and appropriate instruction so that these conditions can have a favorable effect on the spine-related setting parameters.

\section{Declaration of conflicting interests}

The authors declared no conflicts of interest with respect to the authorship and/or publication of this article.

\section{Funding}

The paper was prepared as part of the statutory research program No. DS.212 of Jozef Pilsudski University of Physical Education in Warsaw and was sponsored by the Ministry of Science and Higher Education, Poland.

\section{REFERENCES}

1. Adams MA. Biomechanics of back pain. Acupunct Med 2004;22:178-88.

2. Zemp R, Taylor WR, Lorenzetti S. In vivo spinal posture during upright and reclined sitting in an office chair. Biomed Res Int 2013;2013:916045.

3. Sundstrup E, Jakobsen MD, Andersen CH, Jay K, Andersen LL. Swiss ball abdominal crunch with added elastic resistance is an effective alternative to training machines. Int J Sports Phys Ther 2012;7:372-80.

4. Kim K, Kim YH, Lee S. Shear force allowance in lumbar spine under follower load in neutral standing posture. Acta Bioeng Biomech 2010;12:49-53.

5. Li M, Wong MS, Luk KD, Wong KW, Cheung KM. Timedependent response of scoliotic curvature to orthotic intervention: when should a radiograph be obtained after putting on or taking off a spinal orthosis? Spine (Phila Pa 1976) 2014;39:1408-16.

6. Jackson JA, Banerjee-Guénette P, Gregory DE, Callaghan JP. Should we be more on the ball? The efficacy of accommodation training on lumbar spine posture, muscle activity, and perceived discomfort during stability ball sitting. Hum Factors 2013;55:1064-76.

7. Kang MH, Kim MS. Kang MH, Kim MS. EMG Activity in the Abdominal Muscles and the Kinematics of the Lumbar Spine during Unilateral Upper-limb Resistance Exercises under Stable and Unstable Conditions. J Phys Ther Sci 2014;26:873-5.

8. Rasouli O, Arab AM, Amiri M, Jaberzadeh S. Ultrasound measurement of deep abdominal muscle activity in sitting positions with different stability levels in subjects with and without chronic low back pain. Man Ther 2011;16:388-93.

9. O'Sullivan K, O'Sullivan P, O'Keeffe M, O'Sullivan L, Dankaerts W. The effect of dynamic sitting on trunk muscle activation: a systematic review. Appl Ergon 2013;44:628-35.

10. Gregory DE, Dunk NM, Callaghan JP. Stability ball versus office chair: comparison of muscle activation and lumbar spine posture during prolonged sitting. Hum Factors 2006;48:142-53.

11. Kingma I, van Dieën JH. Static and dynamic postural loadings during computer work in females: Sitting on an office chair versus sitting on an exercise ball. Appl Ergon 2009;40:199-205.

12. Escamilla RF, Lewis C, Bell D, Bramblet G, Daffron J, Lambert $S$, et al. Core muscle activation during Swiss ball and traditional abdominal exercises. J Orthop Sports Phys Ther 2010;40:265-76.

13. McGill SM, Kavcic NS, Harvey E. Sitting on a chair or an exercise ball: various perspectives to guide decision making. Clin Biomech (Bristol, Avon) 2006;21:353-60.

14. Carter JM, Beam WC, McMahan SG, Barr ML, Brown LE. The effects of stability ball training on spinal stability in sedentary individuals. J Strength Cond Res 2006;20:429-35.

15. Schult TM, Awosika ER, Schmunk SK, Hodgson MJ, Heymach BL, Parker CD. Sitting on stability balls: biomechanics evaluation in a workplace setting. J Occup Environ Hyg 2013;10:55-63.

16. Al-Eisa E, Buragadda S, Melam GR. Effect of therapy ball seating on learning and sitting discomforts among Saudi female students. Biomed Res Int 2013;2013:153165.

17. Drzał-Grabiec J, Snela S, Rykała J, Podgórska J, Banaś A. Changes in the body posture of women occurring with age. BMC Geriatr 2013;13:108.

18. Berryman F, Pynsent P, Fairbank J, Disney S. A new system for measuring three-dimensional back shape in scoliosis. Eur Spine J 2008;17:663-72.

19. Scutt ND, Dangerfield PH, Dorgan JC. The relationship between surface and radiological deformity in adolescent idiopathic scoliosis: effect of change in body position. Eur Spine J 1996;5:85-90.

20. Saad KR, Colombo AS, Ribeiro AP, João SM. Reliability of photogrammetry in the evaluation of the postural aspects of individuals with structural scoliosis. J Bodyw Mov Ther 2012;16:210-6.

21. Ruivo RM, Pezarat-Correia P, Carita AI. Intrarater and interrater reliability of photographic measurement of upper-body standing posture of adolescents. J Manipulative Physiol Ther 2015;38:74-80.

22. Mohokum M, Mendoza S, Udo W, Sitter H, Paletta JR, Skwara A. Reproducibility of rasterstereography for kyphotic and lordotic angles, trunk length, and trunk inclination: a reliability study. Spine (Phila Pa 1976) 2010;35:1353-8.

23. Schroeder J, Reer R, Braumann KM. Video raster stereography back shape reconstruction: a reliability study for sagittal, frontal, and transversal plane parameters. Eur Spine J 2015;24:262-9. 
24. Drzał-Grabiec J, Truszczyńska A, Rykała J, Rachwał M, Snela S, Podgórska J. Effect of asymmetrical backpack load on spinal curvature in school children. Work 2015;51:383-8.

25. Truszczyńska A, Lewkowicz R, Truszczyński O, Wojtkowiak M. Back pain and its consequences among Polish Air Force pilots flying high performance aircraft. Int J Occup Med Environ Health 2014;27:243-51.

26. Weaver H, Vichas D, Strutton PH, Sorinola I. The effect of an exercise ball on trunk muscle responses to rapid limb movement. Gait Posture 2012;35:70-7.

27. Scott IR, Vaughan AR, Hall J. Swiss ball enhances lumbar multifidus activity in chronic low back pain. Phys Ther
Sport 2015;16:40-4

28. Vergara M, Page A. Relationship between comfort and back posture and mobility in sitting-posture. Appl Ergon 2002;33:1-8.

29. Ainscough-Potts AM, Morrissey MC, Critchley D. The response of the transverse abdominis and internal oblique muscles to different postures. Man Ther 2006;11:54-60.

30. Tudor-Locke C, Schuna JM Jr, Frensham LJ, Proenca M. Changing the way we work: elevating energy expenditure with workstation alternatives. Int J Obes (Lond) 2014;38:755-65. 